ISSN 0104-4443

Licenciado sob uma Licença Creative Commons

\title{
Compulsão à repetição no contexto analítico para Winnicott ${ }^{1}$
}

\author{
Repetition compulsion withim the psycho-analytical \\ set-up to Winnicott
}

\section{Leopoldo Fulgencio}

Professor do Programa de Pós-Graduação em Psicologia Clínica da PUC-Campinas, Campinas, SP - Brasil, e-mail: leopoldo.fulgencio@gmail.com

\section{Resumo}

Neste artigo pretendo fazer uma análise da alternativa que Winnicott dá à compreensão do fenômeno caracterizado por Freud como sendo o da compulsão à repetição. Depois de retomar a posição de Freud, mostro que Winnicott faz referência à expressão

1 Artigo elaborado a partir de conferência apresentada no III Congresso Internacional de Filosofia da Psicanálise, realizado em novembro de 2009 em Curitiba, na PUCPR, e promovido pelo G.T. Filosofia e Psicanálise da Anpo. Este artigo corresponde a um dos trabalhos que pretendem mostrar que Winnicott redescreveu uma série de conceitos utilizados na psicanálise de Freud e Klein, dando a eles um sentido e um referente diferente dos que tinham quando foram propostos. Greenberg e Mitchell $(1983$, p. 139) já haviam comentado esse tipo de atitude ao afirmarem: "Winnicott conserva a tradição de maneira curiosa, em grande parte distorcendo-a. A sua interpretação dos conceitos freudianos e kleinianos é tão idiossincrática e tão pouco representativa da formulação e intenção originais deles a ponto de torná-las, às vezes, irreconhecíveis. Ele reconta a história das ideias psicanalíticas não tanto como se desenvolveu, mas como ele gostaria que tivesse sido, reescrevendo Freud para torná-lo um predecessor mais claro e mais fácil da própria visão de Winnicott". 
compulsão à repetição em apenas dois momentos de sua obra: um para referir-se a uma criança neurótica que precisa retomar a situação traumática, experienciando-a novamente no quadro do contexto analítico; outro, no qual ele se refere a falhas no início do processo de amadurecimento de alguns pacientes, que os levariam, então, a buscar a situação penosa externa para colocá-la dentro do seu controle onipotente. Procura-se defender que Winnicott substituiu a questão metapsicológica da compulsão à repetição pela questão da regressão à dependência, o que colocaria o si mesmo do paciente em uma situação em que ele pode se desfazer de suas defesas, retornando a uma situação anterior à do trauma e à edificação de defesas; isso, quando sustentado adequadamente pelo ambiente, tornaria possível fazer um tipo de correção da experiência passada, integrando-a à pessoa total do paciente, retomando o processo de amadurecimento a partir dessa nova posição do si mesmo.

Palavras-chave: Compulsão à repetição. Regressão. Amadurecimento. Dependência. Integração.

\section{Abstract}

The purpose of this article is to analyze Winnicott's perspective on the understanding of the phenomenon seen by Freud as the repetition compulsion. After presenting Freud's point of view on this issue, I will show that Winnicott uses the expression repetition compulsion only in two moments of his work: firstly to refer to a situation in which a neurotic child needs to go back to the traumatic situation and experience it again in the analytical context; secondly to refer to failures at the beginning of the maturation process of some patients which would make them look for an external painful situation to submit it to their omnipotent control. We sustain that Winnicott replaced the issue of the metapsychological repetition compulsion by that of regression to dependence which would put the self of the patient in a situation which makes him discard his defenses going back to a situation before that of the trauma and that of the construction of his defenses; when this is adequately supported by the environment, it enables the correction of the past experience, integrating it to the whole person of the patient who restarts the maturation process from this new position of the self.

Keywords: Repetition compulsion. Regression. Maturation. Dependence. Integration. 


\section{Introdução}

Considerando que Freud descreveu alguns comportamentos repetitivos (dentro e fora do contexto analítico) como impulsionados por uma compulsão à repetição, associando a essa compulsão a ideia metapsicológica de uma pulsão de morte, e que Winnicott rejeita a teorização de tipo metapsicológica (FULGENCIO, 2006, 2007), avaliando a pulsão de morte como um erro de Freud (WINNICOTT, [1987] 1990a, p. 42) ${ }^{2}$ e um conceito a ser abandonado (WINNICOTT, [1989] 1994d, p. 242), poder-se-ia perguntar como Winnicott compreenderia ${ }^{3}$ esses comportamentos explicados por Freud?

\section{Objetivos empíricos e metapsicológicos da repetição para Freud}

Em termos descritivos, Freud toma a situação na qual uma criança repete uma brincadeira com um carretel (fazendo-o desaparecer e aparecer, a seu comando, no seu campo de visão), como um protótipo da atividade do brincar, mas também como um modelo para explicar a repetição de uma situação traumática (a mãe desaparece) vivida passivamente, em uma encenação dessa mesma situação (o carretel como a mãe que some e aparece) agora experimentada sob seu controle, de forma ativa e não mais passiva (FREUD, 1920). ${ }^{4}$

Em termos metapsicológicos, Freud considera que a repetição de situações traumáticas, mais ou menos explícitas, visa - nada mais - a descarregar uma excitação que está presente, reprimida, no interior do

2 Estarei citando Winnicott a partir da classificação feita por Knud Hjulmand (1999), considerando que a publicação das obras completas de Winnicott seguirá esse padrão de referência (ABRAM, 2008).

30 uso dos termos explicação e compreensão corresponde a uma escolha epistemológica. George Henrik von Wright (1971), no seu livro Explanation and Understanding, faz uma distinção entre a procura de explicações - referindo-se à procura de relações causais para explicar os movimentos (por exemplo, as explicações de causas que levam uma máquina a funcionar de tal e tal maneira, numa sequência finita e sem lacunas de relações de determinação entre suas partes); e de compreensões referindo-se à procura dos sentidos, intenções, que estariam colocados como estado na gênese dos movimentos (por exemplo, no que se refere às ações humanas ou do ser vivo como movidas por sentidos ou intenções e não como uma sequência de causas e efeitos do tipo mecânico ou dinâmico).

4 Estarei citando Freud a partir da classificação feita por James Strachey na Standard Edition. 
aparelho psíquico. A compulsão à repetição seria a expressão metapsicológica de uma tendência, um impulso, que caracterizaria todo sistema termodinâmico, que é a busca do nível mais baixo de energia. ${ }^{5}$

\section{Referências para compreensão da repetição na perspectiva de Winnicott}

Defende-se, aqui, que a expressão compulsão à repetição não corresponde a um operador teórico significativo da teoria psicanalítica winnicottiana. Dentre os vários motivos para esse fato pode-se ressaltar um argumento central que diz respeito à rejeição que Winnicott faz da teorização metapsicológica na psicanálise. As únicas duas vezes que Winnicott usa essa expressão correspondem a comentários laterais, que acabam por remeter a situação e sua explicação clínica a outros aspectos da teoria psicanalítica winnicottiana, em especial à questão da necessidade de regressão.

Em 1951, na sua resenha do livro de Fairbairn, escrita em parceria com Masud Khan, Winnicott ([1953] 1994a) se refere à compulsão à repetição como uma necessidade do paciente (que ainda não atingiu o estágio de integração em uma unidade pessoal) de retomar a situação penosa para integrá-la na sua área de controle onipotente. Em 1955, no seu "Aspectos clínicos e metapsicológicos da regressão no contexto analítico", Winnicott se refere a um menino, neurótico, em relação ao qual, na situação analítica, "poder-se-ia esperar que ocorressem atuações com as quais seria necessário lidar, uma compulsão à repetição associada ao trauma original" (WINNICOTT, [1955] 1978a, p. 379).

Ao descrever a situação inicial, especificando o que Winnicott caracteriza como sendo a ilusão do bebê e a adaptação que o ambiente faz, podemos compreender o que ele compreende como sendo a área de controle onipotente ou área da ilusão de onipotência:

5 Richard Simanke (a quem agradeço a leitura deste artigo e suas sugestões) me chamou a atenção para uma diferenciação fundamental entre a repetição (como um fenômeno clínico observável por Freud) e a compulsão à repetição (como uma formulação mais propriamente metapsicológica, em relação à qual Freud associa, como motor, o conceito, também metapsicológico, de pulsão de morte).

Rev. Filos., Aurora, Curitiba, v. 23, n. 33, p. 493-506, jul./dez. 2011 
em algum ponto teórico no início do desenvolvimento de cada indivíduo humano, este é capaz, dentro de um contexto fornecido pela mãe, de conceber a idéia de algo que irá satisfazer a necessidade que surge a partir da tensão instintiva. Não se pode dizer que o bebê saiba desde o início o que será criado. Neste momento a mãe se faz presente. Da maneira usual, ela dá ao bebê o seu seio e o seu anseio potencial por alimentar. A adaptação da mãe à necessidade do bebê, quando suficientemente boa, dá a este a ilusão de que existe uma realidade externa que corresponde à sua capacidade de criar. Dito de outro modo, há uma superposição entre o que a mãe fornece e o que o bebê é capaz de conceber (WINNICOTT, 1953, p. 27-28).

A adaptação ambiental fornecerá a ilusão de que, das necessidades do bebê decorre, como uma consequência natural, o surgimento de um objeto adequado para satisfazê-las (WINNICOTT, [1955] 2000a). É, na verdade, o ambiente (a mãe ou quem faz as vezes da mãe) que-interpretando o que o bebê precisa, em uma comunicação profunda com esse bebê - oferece os objetos de forma adequada a serem encontrados, ou melhor, do ponto de vista do observador encontrados, mas do ponto de vista do bebê (dado não haver lugar para uma realidade não-self), criados por ele. Para o bebê, os objetos advêm diretamente de suas necessidades, como se delas fossem criados, ainda que do ponto de vista do observador uma miríade de adaptações do ambiente esteja em jogo (WINNICOTT, [1955] 2000a, [1988] 1990b). É a essa situação na qual os objetos surgem como decorrência das necessidades do bebê - sem que ele tenha nem mesmo que fazer a ação (sentida como uma ação como tal) de criar os objetos - que Winnicott caracteriza como sendo uma experiência de ilusão de onipotência (WINNICOTT, [1988] 1990b). Certamente, quando ele diz que um paciente precisa voltar a uma área de controle onipotente, é a essa área da ilusão de onipotência que ele está se referindo.

$\mathrm{Na}$ continuidade do processo de amadurecimento, sustentado pelo ambiente, essa ilusão de onipotência deixa de ser o padrão de relação com a realidade, ou seja, dessa realidade totalmente subjetiva do início, o bebê, na saúde, passa a relacionar-se com uma realidade transicional (a dos fenômenos e objetos transicionais) em direção à integração que permite o reconhecimento de uma realidade não-Eu objetivamente dada. 
A onipotência é perdida ou destruída, mas a ilusão de relacionar-se com um mundo que diz respeito ao si mesmo, um mundo que pode ser operado a partir do si mesmo, sem perda em demasia da espontaneidade, permanece (WINNICOTT, [1955] 2000a, [1988] 1990b). Na saúde, essa área da ilusão, área dos fenômenos subjetivos, pode ser sobreposta à área objetiva da realidade externa, pode ser vivida em conjunção com a realidade criada-encontrada dos fenômenos transicionais; enquanto, na doença, tudo que é não-eu é intolerável (WINNICOTT, [1955] 2000a, p. 29).

Com o desenvolvimento e amadurecimento do bebê e/ou da criança também surgem outras conquistas, que certamente dependem da sustentação ambiental. A integração contínua implica aumento na capacidade de lidar com os diversos tipos de realidade (subjetiva, transicional, objetivamente dada como externa), o que implica dizer que em cada ponto desse processo também há limites na capacidade de lidar com o mundo. Da mesma maneira que nós, adultos, temos limites, por exemplo, na nossa capacidade imaginativa (tentem imaginar objetivamente 1.932.437 bolas de bilhar), o bebê e/ou a criança também os teria. Na linguagem de Winnicott pode-se afirmar que cabe à maturidade do ego, em cada fase do amadurecimento, poder ou não lidar com a realidade que ele vive. ${ }^{6}$

Quando alguma coisa ocorre para além dessa capacidade (o que depende de cada pessoa em cada momento e em cada ambiente específico) teríamos uma quebra na possibilidade de agir no mundo a partir de si mesmo, ou seja, uma quebra na continuidade do ser, ou seja, teríamos um acontecimento que interrompe o processo de amadurecimento.

Consideremos uma falha do ambiente em um momento precoce do amadurecimento: algo acontece, mas não existe a capacidade, por

6 A distinção entre estes termos (self e ego) é ponto não muito claro em Winnicott. Tomarei, aqui, sem me deter nas justificativas e provas dessa opção, as seguintes diferenciações terminológicas e conceituais, apoiando-me nos textos de Winnicott: ao self considerarei todo tipo de integração que fornece um agente para que uma experiência possa se dar, sempre singular e ligada a contingências dos acontecimentos (WINNICOTT, [1964] 1994b); ao ego, darei dois sentidos: o primeiro, entendendo-0 como "tendência inata à integração" (WINNICOTT, [1965] 1983b, p. 55), e, segundo, como caracterizando um tipo de integração em que há uma unidade do sujeito (que reúne em si, como o nome de um conjunto de vivências, a diversidade de experiências do self). Sobre os diversos graus de integração, com a chegada na conquista do status do Eu Sou, veja Winnicott ([1955] 2000a, [1958] 1978b); e sobre a integração como pessoa inteira, veja Winnicott ([1955] 1978a, [1988] 1990b).

Rev. Filos., Aurora, Curitiba, v. 23, n. 33, p. 493-506, jul./dez. 2011 
falta de sustentação ambiental ou por imaturidade, desse vivido ser abarcado pela pessoa (WINNICOTT, [1974] 1994c). Nessas condições, o que foi vivido não foi experienciado, ficando, por assim dizer, congelado (WINNICOTT, [1955] 1978a), à espera de melhores condições ambientais e pessoais para ser, então, experienciado e integrado à personalidade total do paciente (WINNICOTT, [1974] 1994c). O que fica "guardado" não é nenhum conteúdo, mas algo que ainda não foi experienciado, ao que Winnicott caracteriza como sendo um tipo de "morte fenomenal" (WINNICOTT, [1974] 1994c).

Winnicott diz, nesses casos, que algo do passado não foi vivido e o paciente procura esse não vivido no seu presente e no seu futuro: "em outras palavras, o paciente tem de continuar procurando o detalhe passado que ainda não foi experienciado, e esta busca assume a forma de uma procura deste detalhe no futuro" (WINNICOTT, [1974] 1994c, p. 73). Esse tipo de procura pode ser confundido com uma compulsão à repetição. No entanto, não é a repetição da situação traumática que está em jogo, mas sim a regressão necessária para que uma experiência possa ser vivida e, então, integrada na história de vida do paciente (WINNICOTT, [1974] 1994c).

O descongelamento da situação da falha ambiental, com um dos objetivos a ser alcançado no curso do tratamento psicanalítico, corresponde ao descongelamento das defesas e o retorno a uma fase anterior à da falha, para que o amadurecimento possa ser retomado (WINNICOTT, [1955] 1978a).

\section{Repetição e regressão para Winnicott}

Caberia perguntar: de que tipo é a experiência traumática a ser retomada? Que tipo de defesas estão disponíveis para lidar com as situações traumáticas em quais momentos do amadurecimento? Grosso modo, devemos distinguir duas situações: aquela dos pacientes que tiveram cuidados suficientemente bons no período da primeira infância e aqueles que não tiveram esses cuidados (WINNICOTT, [1989] 1994d). 
Tanto em um caso como em outro se trata de, no tratamento, corrigir a experiência passada revivendo-a. Trata-se, pois, de explicar qual é o sentido disso para Winnicott. Ao referir-se ao tratamento de pacientes neuróticos, ele afirma que o tratamento analítico desses casos

exige que o analista seja capaz de suportar a regressão real à dependência, enquanto a segunda necessita de algo diferente: da capacidade para tolerar idéias e sentimentos (amor, ódio, ambivalência, etc.) e para compreender processos, e também para demonstrar essa compreensão pela expressão adequada através da linguagem (a interpretação daquilo que o paciente está justamente em condições de admitir conscientemente) (WINNICOTT, [1988] 1990b, p. 79-80).

Na neurose, o paciente alcançou a integração que torna possível relacionar-se consigo e com os outros como pessoas inteiras, vivendo essas relações no quadro do cenário edípico (WINNICOTT, [1988] 1990b). Na situação e vivência do complexo de Édipo a pessoa viverá conflitos e emoções relacionais que podem ser intoleráveis, levando-a a reprimi-las como um mecanismo de defesa, o que gerará um inconsciente reprimido que, por sua vez, permanece como uma situação presente "drenando recursos do Ego" (WINNICOTT, [1988] 1990b, p. 74). Para Winnicott, a situação analítica, com pacientes neuróticos, não visa propriamente a reencenar a situação edípica traumática, mas interpretá-la (WINNICOTT, [1955] 1978a), retomar o inconsciente reprimido de modo que o paciente possa experienciar o reprimido de uma maneira em que consiga diferenciar entre a realidade e a fantasia (WINNICOTT, [1988] 1990b), tendo condições de sustentação ambiental que lhe deem a possibilidade de agir a partir de si mesmo (com um ego assim fortalecido) na reencenação das relações interpessoais na neurose de transferência. Não há nenhuma descarga sendo procurada, mas sim a busca da integração de efetivas relações interpessoais que, ao se atualizarem na experiência relacional com o analista, corrigem a experiência passada vivida como intolerável, como não integrável no seu ego total.

Para os pacientes não neuróticos (ou seja, aqueles que sofreram falhas ambientais significativas em momentos precoces do amadurecimento) também é o caso de corrigir uma experiência traumática passada, 
mas, agora, a situação muda de foco, pois a atenção recai "no desenvolvimento do ego e na dependência, e neste caso quando falamos da regressão estaremos imediatamente falando da adaptação do ambiente com seus êxitos e suas falhas" (WINNICOTT, [1955] 1978a, p. 380).

No seu artigo "Aspectos clínicos e metapsicológicos da regressão no contexto analítico", Winnicott se refere à situação de regressão à dependência como algo que só pode ocorrer se o paciente tiver uma organização egoica. Ele descreve, então, esse processo e suas condições, indicando tanto o que ocorreu na situação traumática quanto o que deve ocorrer idealmente na situação analítica (WINNICOTT, [1955] 1978a). Ao tratar do tema do falso e do verdadeiro self, Winnicott também se refere a uma situação em que o paciente se protege do ambiente colocando um anteparo: no momento em que ocorreu uma falha do ambiente no passado, quando o paciente já havia conquistado certa integração do seu eu, este reage protegendo esse eu verdadeiro com o desenvolvimento de um falso eu para fazer frente à falha ambiental (WINNICOTT, [1965] 1983a). Desse tipo de mecanismo de defesa pode surgir tanto o falso self quanto a atitude antissocial, atitude que é um tipo de grito de socorro, reivindicação dirigida ao ambiente para que restitua ao indivíduo a confiabilidade (no ambiente) que lhe foi retirada. Nessas condições ocorre também o surgimento da esperança de que, ao encontrar uma situação ambiental confiável, ele poderá corrigir a experiência traumática (WINNICOTT, [1989] 1994e). A repetição da atitude antissocial é um tipo de grito de socorro dirigido ao ambiente (WINNICOTT, [1989] 1994e). Nesses casos o paciente pode, então, retomar o seu desenvolvimento que havia sido interrompido (WINNICOTT, [1958] 2000b).

Winnicott está, ao fazer esse tipo de descrição, introduzindo uma ideia nova na compreensão do processo de amadurecimento: "a idéia de que é normal e saudável que o indivíduo seja capaz de defender o eu contra falhas ambientais específicas através do congelamento da situação da falha" (WINNICOTT, [1955] 1978a, p. 378). A isso se deve acrescentar que tal operação é acompanhada de uma concepção e uma esperança de que "em algum momento futuro haverá oportunidade para uma nova experiência, na qual a situação da falha poderá ser descongelada e revivida, com o indivíduo num estado de regressão dentro de um ambiente 
capaz de prover a adaptação adequada" (WINNICOTT, [1955] 1978a, p. 378). No trabalho analítico trata-se, pois, de criar as condições de sustentação ambiental para que o paciente possa regredir em busca de corrigir uma experiência passada: “a cura só chega se o paciente atingir o estado original de colapso (WINNICOTT, [1989] 1994d, p. 99).

Quando o indivíduo regride, não é propriamente à situação da falha ambiental; ele regride à dependência, retomando uma situação anterior à da falha, o que possibilitaria que ele descongelasse as suas defesas contra a falha ambiental, estando, assim, livre para retomar seu processo de amadurecimento a partir de um ego fortalecido pela nova sustentação ambiental. Para Winnicott, o processo de tratamento psicanalítico precisa dar condições para que o paciente possa voltar a um "momento anterior àquele em que as intrusões tornaram-se múltiplas e impossíveis de controlar" (WINNICOTT, [1958] 1978c, p. 275), momento anterior àquele em que ele precisou construir defesas, as quais permanecem como sintomas.

O descongelamento da situação traumática não significa exatamente a repetição da situação traumática, mas uma regressão à situação de dependência que recoloca o eu (do paciente) em uma situação anterior à traumática, em condições nas quais ele pode se desfazer das suas defesas antigas e retomar o processo de amadurecimento integrando o que foi vivido no passado na sua personalidade.

\section{A necessidade de retomar o processo de amadurecimento}

Em todos os casos, o que temos, para Winnicott, é a necessidade de uma sustentação ambiental para que a correção da experiência traumática (que interrompeu o processo de amadurecimento) possa ocorrer. A questão que Winnicott se coloca não é propriamente a do retorno às relações objetais, tal como foram vividas, para descatexizá-las, tal como Freud supôs. Para ele, o importante é que exista uma situação ambiental que torne possível ao paciente retomar seu processo de amadurecimento a partir do si mesmo não reativo, não defendido. A questão metapsicológica da compulsão à repetição pode ter sido substituída 
pela questão empírica da regressão à dependência e da necessidade da integração e, por sua vez, a questão da regressão está relacionada com o tipo de ambiente que a análise pode fornecer. Dizendo de outra maneira, a questão do manejo da situação analítica tem ligação direta com o tipo de ambiente necessário para que os pacientes possam corrigir, regredindo à dependência, suas experiências penosas passadas.

Trata-se, para Winnicott, de fornecer as condições para que o amadurecimento, que foi interrompido, possa vir a ocorrer. Para que o amadurecimento seja retomado, será necessário também que a solução para os problemas vividos seja encontrada pelo próprio paciente, como uma criação sua: "num contexto profissional, dado o comportamento profissional apropriado, pode ser que o doente encontre uma solução pessoal para problemas complexos da vida emocional e das relações interpessoais; o que fizemos não foi aplicar um tratamento, mas facilitar o crescimento" (WINNICOTT, [1986] 1989, p. 113-114).

Quando ocorrem falhas que interrompem o processo de amadurecimento, diz Winnicott, "a tarefa da criança é provocar condições nas quais a repetida correção da falha seja um padrão para a vida" (WINNICOTT, [1968] 1988, p. 87). Mas essa repetição não é da falha, ela mesma, e sim da procura da retomada das condições que tornam possível corrigir a falha, ou seja, das condições ambientais e pessoais que não produziriam os mecanismos de defesa empregados no passado, deixando o caminho livre para a continuidade do processo de amadurecimento. Em outros termos, não há impulso para a repetição, mas tão somente tendência para a integração que depende da sustentação ambiental, o que visa, em última instância, retomar o processo de amadurecimento.

A repetição ou busca da situação traumática, compreendida agora no contexto da situação analítica, corresponde a uma procura da retomada da sustentação ambiental, em um sentido uma regressão à dependência, para que o self possa agir a partir de si mesmo na integração da situação traumática passada no campo de seu controle, no campo da sua ilusão, ou seja, no campo onde o self age a partir de si mesmo sem demasiada perda de espontaneidade (WINNICOTT, [1965] 1983c). Trata-se de colocar novamente em marcha o processo de 
amadurecimento afetivo, retornando a condições anteriores àquelas em que o paciente teve que se defender, para, nessas novas condições, agir a partir de si mesmo colocando o que foi a experiência traumática no campo de seu controle, podendo até mesmo se adaptar ou aceitar a realidade do que o traumatizara, desde que seja mantido esse lugar a partir de onde o self age sem ser aniquilado.

\section{Referências}

ABRAM, J. Donald Woods Winnicott (1896-1971): a brief introduction. International Journal of Psychoanalysis, v. 89, n. 6, p. 1189-1217, 2008.

FREUD, S. Au-delà du principe du plaisir. In: FREUD, S. Sigmund Freud: Oeuvres complètes. Paris: PUF, 1920.

FULGENCIO, L. Winnicott e uma psicanálise sem metapsicologia. Revista de Filosofia e Psicanálise Natureza Humana, v. 8, n. 1, p. 401-420, 2006.

FULGENCIO, L. Winnicott's rejection of the basic concepts of Freud's metapsychology. The International Journal of Psychoanalysis, v. 88, n. 2, p. 443461, 2007.

GREENBERG, J. R.; MITCHELL, S. A. Relações objetais na teoria psicanalítica. Porto Alegre: Artes Médicas, 1983.

HJULMAND, K. Lista completa das publicações de D. W. Winnicott. Revista de Filosofia e Psicanálise Natureza Humana, v. 1, n. 2, p. 459-517, 1999.

WINNICOTT, D. W. Objetos transicionais e fenômenos transicionais. In: WINNICOTT, D. W. O brincar e a realidade. Rio de Janeiro: Imago, 1953. p. 13-44.

WINNICOTT, D. W. Aspectos clínicos e metapsicológicos da regressão no contexto psicanalítico. In: WINNICOTT, D. W. Da pediatria à psicanálise. Rio de Janeiro: Francisco Alves, 1978a. p. 374-392. Publicado originalmente em 1955.

WINNICOTT, D. W. A agressividade e sua relação com o desenvolvimento emocional. In: WINNICOTT, D. W. Da pediatria à psicanálise. Rio de Janeiro: Francisco Alves, 1978b. p. 288-304. Publicado originalmente em 1958. 
WINNICOTT, D. W. Memórias do nascimento, trauma do nascimento e ansiedade. In: WINNICOTT, D. W. Da pediatria à psicanálise. Rio de Janeiro: Francisco Alves, 1978c. p. 254-276. Publicado originalmente em 1958.

WINNICOTT, D. W. Distorção do ego em termos de falso e verdadeiro self. In: WINNICOTT, D. W. O ambiente e os processos de maturação. Porto Alegre: Artes Médicas,1983a. p. 128-139. Publicado originalmente em 1965.

WINNICOTT, D. W. A integração do ego no desenvolvimento da criança. In: WINNICOTT, D. W. O ambiente e os processos de maturação. Porto Alegre: Artes Médicas, 1983b. p. 55-61. Publicado originalmente em 1965.

WINNICOTT, D. W. Da dependência à independência no desenvolvimento do indivíduo. In: WINNICOTT, D. W. O ambiente e os processos de maturação. Porto Alegre: Artes Médicas, 1983c. p. 79-87. Publicado originalmente em 1965.

WINNICOTT, D. W. A comunicação entre o bebê e a mãe e entre a mãe e o bebê: convergências e divergências. In: WINNICOTT, D. W. Os bebês e suas mães. São Paulo: M. Fontes, 1988. p. 79-92. Publicado originalmente em 1968.

WINNICOTT, D. W. A cura. In: WINNICOTT, D. W. Tudo começa em casa. São Paulo: M. Fontes, 1989. p. 87-93. Publicado originalmente em 1986.

WINNICOTT, D. W. O gesto espontâneo. São Paulo: M. Fontes, 1990a. Publicado originalmente em 1987.

WINNICOTT, D. W. Natureza humana. Rio de Janeiro: Imago, $1990 \mathrm{~b}$. Publicado originalmente em 1988.

WINNICOTT, D. W. Resenha de Psychoanalytic Studies of the Personality, de W. R. D. Fairbairn. In: WINNICOTT, D. W. Explorações psicanalíticas. Porto Alegre: Artes Médicas, 1994a. Publicado originalmente em 1953.

WINNICOTT, D. W. Resenha de Memories, Dreams, Reflections, de C. J. Jung. In: WINNICOTT, D. W. Explorações psicanalíticas. Porto Alegre: Artes Médicas, 1994b. p. 365-372. Publicado originalmente em 1964.

WINNICOTT, D. W. O medo do colapso. In: WINNICOTT, D. W. Explorações psicanalíticas. Porto Alegre: Artmed,1994c. p. 70-76. Publicado originalmente em 1974. 
WINNICOTT, D. W. A psicologia da loucura: uma contribuição da psicanálise. In: WINNICOTT, D. W. Explorações psicanalíticas. Porto Alegre: Artes Médicas, 1994d. Publicado originalmente em 1989.

WINNICOTT, D. W. Psiconeurose na infância. In: WINNICOTT, D. W. Explorações psicanalíticas. Porto Alegre: Artes Médicas, 1994e. Publicado originalmente em 1989.

WINNICOTT, D. W. O uso do objeto no contexto de Moisés e o monoteísmo. In: WINNICOTT, D. W. Explorações psicanalíticas. Porto Alegre: Artes Médicas, 1994f. Publicado originalmente em 1989.

WINNICOTT, D. W. A posição depressiva no desenvolvimento emocional normal. In: WINNICOTT, D. W. Da pediatria à psicanálise. Rio de Janeiro: Imago, 2000a. Publicado originalmente em 1955.

WINNICOTT, D. W. A tendência anti-social. In: WINNICOTT, D. W. Da pediatria à psicanálise. Rio de Janeiro: Imago, 2000b. Publicado originalmente em 1958.

WRIGHT, G. H. von. Explanation and understanding. Ithaca: Cornell University Press, 1971.

Recebido: 10/06/2011

Received: 06/10/2011

Aprovado: $21 / 07 / 2011$

Approved: 07/21/2011 